\title{
Detection of circulating tumour cells on mRNA levels with established breast cancer cell lines
}

\author{
MICHAEL ZEBISCH, ALEXANDRA C. KÖLBL, ULRICH ANDERGASSEN, STEPHAN HUTTER, \\ JULIA NEUGEBAUER, VERENA ENGELSTÄDTER, MARIA GÜNTHNER-BILLER, \\ UDO JESCHKE, KLAUS FRIESE and BRIGITTE RACK
}

Department of Obstetrics and Gynaecology, Ludwig-Maximilians University of Munich, Munich, Germany

Received July 18, 2012; Accepted August 22, 2012

DOI: 10.3892/br.2012.45

\begin{abstract}
Circulating tumour cells were detected and quantified by real-time polymerase chain reaction (PCR) in peripheral blood, based on the fact that the expression of certain genes is upregulated in tumour tissues in comparison to surrounding blood cells. Calibration curves showing gene expression as functions of the number of tumour cells within a blood sample were prepared. Blood samples were therefore spiked with cells of breast cancer cell lines, RNA was extracted, transcribed to complementary DNA (cDNA) and used in real-time PCR reaction on the Cytokeratins (CK) 8, 18 and 19. Calibration curves were generated by Microsoft ${ }^{\mathrm{TM}} \mathrm{Excel}^{\circledR}$. Relative quantification curves of gene expression in different breast cancer cell lines showed no unitary tendencies. The oscillations in the relative quantification curves of gene expression suggested an occurrence of immunological effects, leading to an apparent agglutination of added tumour cells together with the blood cells of the sample. Thus, strategies to obtain evaluable results should be considered.
\end{abstract}

\section{Introduction}

Breast cancer constitutes $28 \%$ of the cancer incidents worldwide and is thereby the most frequently occurring cancer and the most frequent cause of mortality in women. Lethality, which has fortunately been regressive since the 1970s, remains at $30 \%$ over the stages of breast cancer on average.

The main reason for breast cancer-associated mortality is the formation of remote metastases by the primary tumour. Current models assume that cells, dissolving from the primary tumour, migrate to other organs and bone marrow, where

Correspondence to: Professor Udo Jeschke, Ludwig-Maximilians University of Munich, Department of Obstetrics and Gynaecology, Maistrasse 11, D-80337 Munich, Germany

E-mail: udo.jeschke@med.uni-muenchen.de

Key words: circulating tumour cells, detection, quantification, mRNA, real-time polymerase chain reaction, breast cancer they settle down, forming the core for remote metastases (1). The occurrence of these so-called 'circulating tumour cells' (CTCs) in peripheral blood and disseminated tumour cells (DTCs) in bone marrow of patients with epithelial tumours has already been found in numerous studies (1-3). A number of these studies demonstrated that the occurrence of CTCs in blood is linked to a worse prognosis for overall survival in comparison to patients without CTCs $(4,5)$. Several trials have been made to detect CTCs in the peripheral blood of patients. Various methods of analysis are used in laboratories working on this topic, rendering a comparison difficult.

Changes in gene expression levels are important features of tumour cells (6), whereas most genes, regulating the cell cycle control and thereby cell proliferation, are altered, often leading to an increase in cell proliferation. For example, microarray analyses have been carried out to identify genes with changes in expression levels in healthy and breast cancer tissues $(7,8)$. Differences in the expression rates of certain genes are known to have the potential to facilitate a statement on the prognosis of a cancer disease and the opportunity to improve medical treatment $(9,10)$. Such changes in gene expression may also be used for diagnostic purposes. Measurement of gene expression can be performed using polymerase chain reaction (PCR)-based methods, especially real-time PCR. By this method an increase of DNA molecules during PCR reaction is measured by fluorescent reporter molecules such as SYBR-Green. This substance is incorporated in DNA molecules during the reaction (11). If the RNA-depending cDNA-amount of a gene at the beginning of a reaction is high, then the increase in DNA molecules during the reaction is likely to be higher, meaning that a high fluorescence level for the analysed gene at the end of the PCR is evident and can be detected. The DNA-amount at the beginning of a reaction depends on the complementary DNA (cDNA), which is received from isolated mRNA as a result of reverse transcription reaction. The mRNA in turn is isolated from a tissue or cell pellet that is to be analysed.

TaqMan real-time PCR, invented by the Cetus Corporation (Berkeley, CA, USA) in 1991, is one of the most sensitive PCR methods currently available. An additional gene-specific PCR-reagent is coupled to a reporter and a quencher molecule. The quencher represses the fluorescence of the reporter provided they are in close proximity (12). During PCR-reaction, the reporter and quencher are separated by the 
5'-3' exonuclease activity of the polymerase, while a marked increase was detected in the fluorescence signal.

The first step towards a real-time PCR-based quantitative cancer diagnosis is to create calibration curves for the used genes to evaluate the number of cancer cells exhibited at a certain level of gene expression in blood or bone marrow samples.

Therefore, in the present study, blood samples of healthy donors were spiked with determined numbers of breast cancer cell line cells, and treated in the same manner as patient samples (see Materials and methods). Real-time PCR was employed with the Cytokeratin genes (CK) 8, 18 and 19. These genes are also used in the immunohistochemical detection of cancer cells [alkaline phosphatase-anti alkaline phosphatase (APAAP-staining; 13,14)] from bone marrow, and are established markers for epithelial cells in contrast to blood cells.

\section{Materials and methods}

Cell culture. The epithelial breast cancer cell lines used for the experiments were Cama-1,MCF-7, MDA-MB231, derived from mammary gland adenocarcinoma and ZR-75-1, derived from ductal carcinoma. Cells were cultured routinely, according to international standards. After being detached, the cells were counted in a haemocytometer and diluted to adequate concentrations with phosphate-buffered saline (PBS; Biochrome Ltd., Cambridge, UK). Cells were then added to the blood samples taken from healthy donors. Two different experiments were carried out: in the first part, blood samples were spiked with 0 , 10,100 and 1000 cells from the above-mentioned breast cancer cell lines, while in the second part 0, 10, 100, 1000, 10000 and 100000 MCF-7 cells were added per $\mathrm{ml}$ of a blood sample.

Treatment of blood samples. A blood sample $(7.5 \mathrm{ml})$ was collected from a healthy donor in EDTA-tubes to prevent coagulation. The respective number of cell line cells was added to the blood, and the samples were diluted with PBS up to $20 \mathrm{ml}$. For density gradient centrifugation, the samples were carefully layered onto $20 \mathrm{ml}$ of Histopaque ${ }^{\circledR} 1077$ (Invitrogen, Carlsbad, CA, USA) and centrifuged for $30 \mathrm{~min}$ at $400 \mathrm{~g}$. Following centrifugation the buffy coat was aspirated in each case and transferred into new tubes. Two washing steps were carried out using PBS $\left(10 \mathrm{~min}, 250 \mathrm{~g}, 4^{\circ} \mathrm{C}\right)$. The resulting cell pellets were then air dried and frozen at $-80^{\circ} \mathrm{C}$.

RNA isolation. To extract RNA, the cell pellets were defrosted and resuspended in $1 \mathrm{ml}$ TRIzol ${ }^{\circledast}$ LS Reagent (Invitrogen Life Technologies) and $0.2 \mathrm{ml}$ chloroform was added. The solution was vortexed vigorously. Following a centrifugation step at $12000 \mathrm{x} \mathrm{g}$ for $15 \mathrm{~min}$ at $4^{\circ} \mathrm{C}$ the resulting supernatant was aspirated and transferred into a fresh tube, prepared with $500 \mu \mathrm{l}$ cooled isopropanol and $2.5 \mu \mathrm{l}$ glycogen (Invitrogen Life Technologies). The samples were slightly vortexed and stored frozen at $-20^{\circ} \mathrm{C}$ overnight. The following day the samples were centrifuged at $12000 \mathrm{x}$ g for $10 \mathrm{~min}$ at $4^{\circ} \mathrm{C}$. The supernatant was removed and pellets were washed with $1 \mathrm{ml} 75 \%$ ethanol and centrifuged at $12000 \mathrm{xg}$ for $10 \mathrm{~min}$ at $4^{\circ} \mathrm{C}$. The supernatant was removed again and pellets were air-dried and resuspended in $20 \mu 1$ diethylpyrocarbonate (DEPC)-treated water. RNA concentrations and ratios were measured photometrically by a NanoPhotometer ${ }^{\circledR}$ (Implen GmbH, Munich, Germany). Special attention was paid to high-quality templates as only high-quality RNAs were used with absorbance ratios of 260/280 $\mathrm{nm}$ between 1.7 and 1.9.

Reverse transcription. The reverse transcription from RNA to cDNA was carried out using the SuperScript ${ }^{\circledR}$ III First Strand Synthesis Supermix kit (Invitrogen Life Technologies). Therefore, $4 \mu \mathrm{g}$ of RNA, in a maximum volume of $6 \mu \mathrm{l}, 1 \mu \mathrm{l}$ Oligo(dT)-primers and $1 \mu l$ annealing buffer were added to the samples. The preparations were incubated at $65^{\circ} \mathrm{C}$ for $5 \mathrm{~min}$, and immediately chilled on ice for at least $5 \mathrm{~min}$. First strand reaction mix (10 $\mu \mathrm{l})$ and SuperScript ${ }^{\circledR} \mathrm{III} / \mathrm{RNase}$ Out $^{\mathrm{TM}}$ enzyme mix $(2 \mu 1)$ (Invitrogen Life Technologies) were immediately added. The samples were incubated at $50^{\circ} \mathrm{C}$ for $50 \mathrm{~min}$. To inactivate the enzyme reverse transcriptase after completing the reaction, the samples were denatured at $85^{\circ} \mathrm{C}$ for $5 \mathrm{~min}$ and stored at $-20^{\circ} \mathrm{C}$ until use.

Real-time PCR. For each real-time PCR reaction, $2 \mu 1$ cDNA were used together with $1 \mu l$ of gene-specific TaqMan primers (CK8, 18 and 19), $10 \mu 1$ TaqMan Fast Universal PCR Mastermix (Applied Biosystems, Foster City, CA, USA) and $7 \mu \mathrm{l}$ PCR-water. The 96-well plates were run on a 7500 Fast Real Time PCR System (Applied Biosystems). A denaturation step of cDNA at $95^{\circ} \mathrm{C}$ for $20 \mathrm{sec}$ was initially administered, followed by 40 cycles at $95^{\circ} \mathrm{C}$ for $3 \mathrm{sec}$ and $60^{\circ} \mathrm{C}$ for $30 \mathrm{sec}$. Subsequent to each PCR cycle the fluorescence intensity was measured by the system and recorded by the corresponding software [Sequence Detection System ${ }^{\circledast}$ (SDS) Version 1.3.1; Applied Biosystems]. 18S was used in the experiments as an internal reference control for the PCR reaction (15). The primers (Applied Biosystems) used for the experiments were CK8, Hs_02339472_g1; CK18, Hs_01920599_gH; CK19, Hs_00761767_s1 and 18S, Hs_03928990_g1. For each gene and cell amount added to a blood sample, eight reactions were run in the PCR and the means were used for evaluation.

Evaluation of results. Ct-, $\Delta \mathrm{Ct}$ - and $\Delta \Delta \mathrm{Ct}$-values were calculated by the SDS-software (Applied Biosystems), and the threshold was set automatically, $18 \mathrm{~S}$ was used as a calibrator sample. The generated files were exported to Microsoft ${ }^{\mathrm{TM}}$ Excel $^{\circledR}$ and the additional graphs were added in.

\section{Results}

The curves of relative quantification of gene expression did not show consistent tendencies. In the first part of the experiment, in which blood samples were spiked with $0,10,100$ and 1000 cells of various breast cancer cell lines (Cama-1, MDA-MB231, MCF-7 and ZR-75-1), the relative quantification curves for each cell line were similar for CK18 and 19. With the exception of Cama-1, a decrease was detected for the cell lines between the values of 10 and 1000 cells added (Fig. 1A and B).

The strongest decrease was observed for MDA-MB-231. In this cell line, the curve of relative quantification of gene expression was already on the decrease between 10 and 100 cells added and was, notably, not increasing for 1000 cells added to the blood sample. A slight decrease was detected 
A

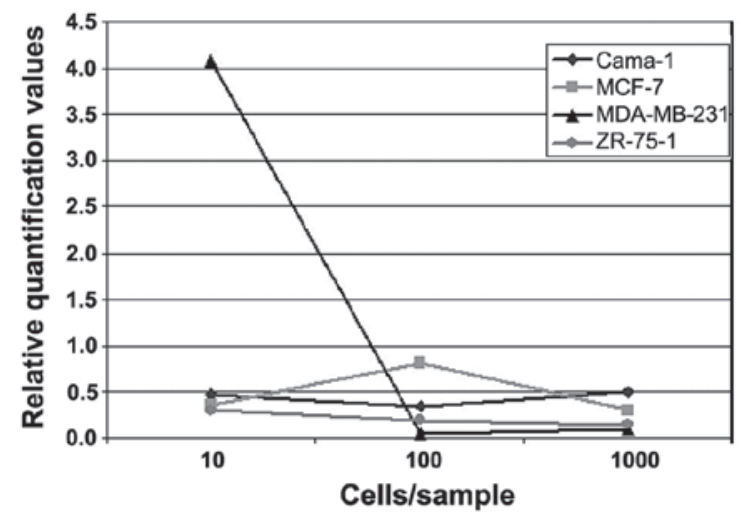

B

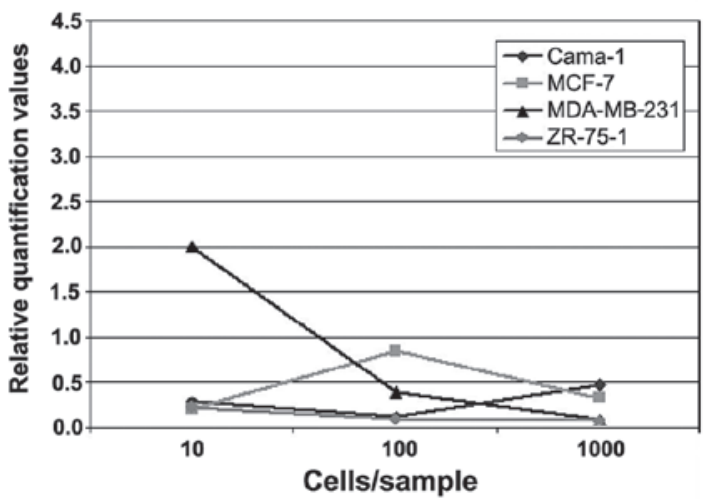

Figure 1. Relative quantification of (A) CK18 and (B) CK19 in the breast cancer cell lines Cama-1, MDA-MB-231, MCF-7 and ZR-75-1.

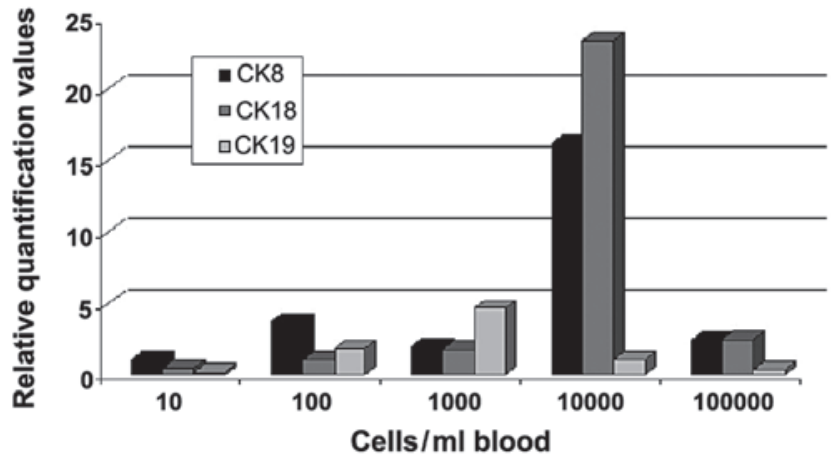

Figure 2. Calibration graph indicating relative quantification of CK8, 18 and 19 in MCF-7 cells is shown.

between 10 and 100 cells per blood sample for the ZR-75-1 sample that was maintained until 1000 cells. The MCF-7-cells showed an increase in the relative quantification values between 10 and 100 cells, although the curves again showed a decrease towards the 1000 cell sample. In the Cama-1 sample, a slight decrease was detected, from 10 to 100 cells. However, an increase was observed from 100 to 1000 cells of the added cell line.

In the second part of the experiment MCF-7 cells were spiked per ml blood sample in steps of $0,10,100,1000$, 10000 and 100000 cells (Fig. 2). The relative quantification values of gene expression for CK8, 18 and 19 were measured. The values for CK8 showed an increase until the $100 \mathrm{MCF}-7$ cell sample. A decrease of the value in the 1000-cell sample was observed, whereas for the 10000-cell sample a strong increase of relative quantification was measured. For the 100000 cells $/ \mathrm{ml}$ blood sample, the curve for CK8 was almost on the decrease again to the value of the 1000-cell sample. For CK18 a slight but steady increase was observed, until the cell number of 1000 cells was added. A strong increase occurred again between 1000 and 10000 cells. The value for 100000 cells being added to the sample was on the decrease as observed for CK8. The relative quantification curve for CK19 appeared markedly different compared to the curves for CK8 and 18. Thus, there was only a slight increase in gene expression values until 1000 cells/ml were added and then a reduction was detected to levels lower than those found for CK8 and CK18.

\section{Discussion}

The best cell line for generating calibration curves for real-time PCR experiments with CK was Cama-1 of the first part of the experiment. Only for this cell line the expected increase in relative quantification of gene expression was seen for the numbers of added cells. ZR-75-1 relative quantification levels were rather low, showing no considerable changes at increasing numbers of cancer cells added. By contrast, MDA-MB-231 showed a marked decrease in the curves between 10 and 100 tumour cells added for CK18, as well as for CK19. This may be due to immunological effects, leading to an apparent agglutination of cancer cell line cells with common blood cells. Similar effects are likely to be the reason for the graph progression of the MCF-7-spiked blood samples. Of note, in the MCF-7 samples an initial increase occurred, however, values of relative quantification showed a decrease for higher numbers of cancer cells added to the blood sample. This finding might also indicate that certain immunological effects between common blood cells and added artificial tumour cells are dependent on cell concentration. Thus, the higher the added cell concentration, the more agglutinative effects occur, altering the results of the PCR.

The second experiment showed rather different tendencies in comparison to the first one (Fig. 2). In this trial, only MCF-7 cells were used for spiking and for the generation of the graphs, for CK8 as well as for CK18 and 19, and showed an increase in relative quantification levels until 100 cells added per ml blood sample and a decrease from the highest cell number used (100000 cell line cells added). For CK8, the sample with 1000 cells per ml added showed an unexpectedly lower value. However, for 10000 cells, the relative quantification value was again elevated. CK18 showed a steady increase of relative quantification values when more cancer cells are added to the sample (until 10000 cells) with the strongest increase being measured between 1000 and 10000 cells. For CK19, an increase in relative quantification values was detected until 1000 cells, followed by a steady decrease. These results seem to confirm the suggestion that 
immunological reactions occur between MCF-7 and common blood cells, rendering MCF-7 cells alone inappropriate for the generation of calibration curves. However, using different artificial breast cancer cell lines may be the key for generating calibration curves, as CTCs are regarded to be of different origins and therefore show histological distinctions. Another aspect that may be relevant is that better results are potentially obtained when tumour cells are added following enrichment of cells by density gradient centrifugation, shortly before the RNA extraction process is started. Fewer cells are likely to be lost during the centrifugation and washing steps and more precise calibration curves could be generated. Adding the cancer cell line cells per $\mathrm{ml}$ of a blood sample used is also important, otherwise real-time PCR detection limits may be undercut (16).

\section{References}

1. Pantel K and Brakenhoff RH: Dissecting the metastatic cascade. Nat Rev Cancer 4: 448-456, 2004.

2. Ring A, Smith IE and Dowsett M: Circulating tumour cells in breast cancer. Lancet Oncol 5: 79-88, 2004.

3. Smerage JB and Hayes DF: The measurement and therapeutic implications of circulating tumour cells in breast cancer. $\mathrm{Br} \mathrm{J}$ Cancer 94: 8-12, 2006.

4. Braun S, Pantel K, Muller P, et al: Cytokeratin-positive cells in the bone marrow and survival of patients with stage I, II, or III breast cancer. N Engl J Med 342: 525-533, 2000.

5. Braun S, Vogl FD, Naume B, et al: A pooled analysis of bone marrow micrometastasis in breast cancer. N Engl J Med 353: 793-802, 2005.

6. Zhang L, Zhou W, Velculescu VE, et al: Gene expression profiles in normal and cancer cells. Science 276: 1268-1272, 1997.
7. Frasor J, Danes JM, Komm B, et al: Profiling of estrogen up- and down-regulated gene expression in human breast cancer cells: insights into gene networks and pathways underlying estrogenic control of proliferation and cell phenotype. Endocrinology 144: 4562-4574, 2004.

8. Hedenfalk I, Duggan D, Chen Y, et al: Gene expression profiles in hereditary breast cancer. N Engl J Med 344: 539-548, 2001.

9. Urban P, Vuaroqueaux V, Labuhn M, et al: Increased expression of urokinase-type plasminogen activator mRNA determines adverse prognosis in ErbB2-positive primary breast cancer. J Clin Oncol 24: 4245-4253, 2006.

10. Taylor KJ, Sims AH, Liang L, et al: Dynamic changes in gene expression in vivo predict prognosis of tamoxifen-treated patients with breast cancer. Breast Cancer Res 12: R39, 2010.

11. Devlin TM: Regulation of gene expression. In: Textbook of Biochemistry with Clinical Correlations. John Wiley \& Sons; 7th edition, pp257, 2010.

12. Holland PM, Abramson RD, Watson R and Gelfand DH: Detection of specific polymerase chain reaction product by utilizing the 5'-3' exonuclease activity of Thermus aquaticus DNA polymerase. Proc Natl Acad Sci USA 88: 7276-7280, 1991.

13. Kurec AS, Baltrucki L, Mason DY and Davey FR: Use of the APAAP method in the classification and diagnosis of hematologic disorders. Clin Lab Med 8: 223-236, 1988.

14. Noack F, Schmitt M, Bauer J, et al: A new approach to phenotyping disseminated tumor cells: methodological advances and clinical implications. Int J Biol Markers 15: 100-104, 2000.

15. Huggett J, Dheda K, Bustin S and Zumla A: Real-time RT-PCR normalisation; strategies and considerations. Genes Immun 6: 279-284, 2005.

16. Datta YH, Adams PT, Drobyski WR, et al: Sensitive detection of occult breast cancer by the reverse-transcriptase polymerase chain reaction. J Clin Oncol 12: 475-482, 1994. 